ABDI: Jurnal Pengabdian dan Pemberdayaan Masyarakat ISSN: 2656-369X (Print), 2684-8570 (Online)

Volume 3 No. 1, Juni 2021

http://abdi.ppj.unp.ac.id/index.php/abdi

Email: abdi@ppj.unp.ac.id

DOI: https://doi.org/10.24036/abdi.v3il.76

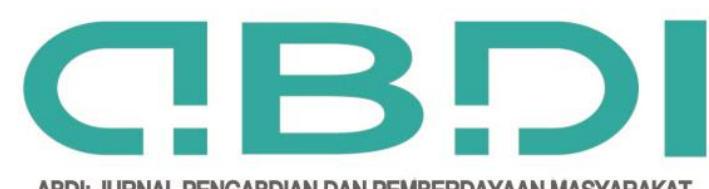

\title{
Pelatihan Pembuatan dan Pemanfaatan Replika Sejarah dan Peta E-Pen Bagi Guru-Guru SMA/MA
}

\author{
Didin Saripudin $^{1}$, Leli Yulifar ${ }^{2}$, Diana Noor Anggraini ${ }^{3}$ \\ ${ }^{1,2}$ Departemen Pendidikan Sejarah, Universitas Pendidikan Indonesia \\ ${ }^{3}$ Program Studi Pendidikan IPS, Universitas Pendidikan Indonesia
}

E-mail: saripudinupi@yahoo.com, leli_yulifar@upi.edu, diana.anggraini@upi.edu

\begin{abstract}
Abstrak
Realita di lapangan menunjukkan bahwa pada umumnya guru masih memiliki kesulitan dalam mengembangkan media pembelajaran Sejarah. Kendala ini disebabkan diantaranya karena kurangnya pendidikan dan pelatihan yang efektif untuk pengembangan profesionalisme guru dalam hal mengembangkan dan memanfaatkan media pembelajaran. Media pembelajaran berupa: 1) replika benda-benda sejarah, manusia purba dan peta elektronik pen (e-pen) persebaran situs pra sejarah di Indonesia, 2) replika benda-benda sejarah pada masa Hindu Budha dan peta e-pen pada masa Hindu Budha, 3) replika benda-benda sejarah pada masa Islam dan peta $e$-pen pada masa Islam. Setiap masa/babak dijadikan satu set/kit. Metode pelatihan ini menggunakan model In/On Training Service. Kegiatan pengabdian ini juga merupakan tindak lanjut dari kepakaran tim pengusul dan penelitian yang dilaksanakan bekerjasama dengan pihak MGMP Sejarah dan Dinas Pendidikan Kabupaten Sukabumi. Hasil pelatihan pengembangan media pembelajaran Sejarah dilaksanakan secara daring dengan tahap IN-ON service. Pelatihan diikuti oleh 60 peserta yang berasal dari Kabupaten Sukabumi. Pelatihan media pembelajaran Sejarah Indonesia yang dihasilkan berupa: replica dan peta e-pen. Setiap masa/babak dijadikan satu set/kit, sehingga pada kegiatan pelatihan guru-guru dikelompokkan menjadi 3 pembabakan dalam membuat media pembelajaran. Penyelenggaraan pelatihan media pembelajaran Sejarah dibagi menjadi empat tahap dilakukan oleh Tim Pengabdian dan Panitia Penyelenggara, yaitu Tahap Persiapan, Tahap Pelaksanaan Pelatihan, Tahap Evaluasi, dan Tahap Rencana Tindak Lanjut yang dilakukan secara daring. Pelatihan ini melibatkan MGMP Sejarah Kabupaten Sukabumi, LPPM UPI, IKA Departemen Pendidikan Sejarah, dan mahasiswa Departemen Pendidikan Sejarah.
\end{abstract}

Kata kunci: Media Pembelajaran; Pengembangan; Peta Elektronik Pen; Replika; Sejarah Indonesia.

Abstract

The reality in the field shows that generally teachers still have difficulties in developing History learning media. These constraints are caused, among others, due to the lack of effective education and training for the development of teacher professionalism in developing and utilizing learning media. Learning media in the form of; 1) replicas of historical objects, ancient humans and electronic map pen (e-pen) distribution of prehistoric sites in Indonesia, 2) replicas of historical objects during the Hindu Buddhist era and e-pen maps during the Hindu Buddhist era. 3) replicas of historical objects during the Islamic period and e-pen maps during the Islamic period. Each period / chapter is made into a set / kit. This training method uses the In / On Training Service model. This service activity is also a follow-up to the expertise of the proposer and research team carried out in collaboration with the MGMP History and the Sukabumi District Education Office. The results of the training in the development of History learning media are carried out online with the IN-ON service stage. The training was attended by 60 participants from Sukabumi Regency. The resulting training on Indonesian History learning media consists of replica and e-pen maps. Each period / round is made into a set / kit, so that in the training activities the teachers are grouped into 3 batches in making learning media. The implementation of the History learning media training is divided into four stages carried out by the Service Team and the Organizing Committee, namely the Preparation Stage, the Training Implementation Stage, the Evaluation Stage, and the Follow-up Planning Stage which are carried out online. This training involved the MGMP of History of Sukabumi Regency, LPPM UPI, IKA of the Department of History Education, and students of the Department of History Education.

Keyword: Development; Electronic Pen; Indonesia History; Learning Media; Replicas. 
Didin Saripudin, Leli Yulifar, Diana Noor Anggraini Pelatihan Pembuatan dan Pemanfaatan Replika Sejarah dan Peta E-Pen Bagi Guru-Guru SMA/MA

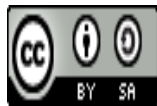

\section{Pendahuluan}

Media pembelajaran merupakan komponen penting dalam proses pembelajaran terutama pada pembelajaran Sejarah. Media dijadikan alat bantu untuk mengurangi verbalisme siswa oleh guru-guru Sejarah di lapangan. Selain itu pengadaan media pembelajaran sejarah juga mendekatkan siswa dengan subjek sejarah (Saripudin, 2009)(Tarunasena, 2012). Kajian menunjukkan bahwa media pembelajaran memiliki manfaat sebagai berikut: 1) memperjelas penyajian pesan agar mudah dipahami; 2) mengatasi keterbatasan ruang, waktu dan daya indera; 3) menarik perhatian pembelajar sehingga dapat menumbuhkan motivasi belajar dan sikap positif terhadap proses belajar; 4) membelajarkan siswa lebih aktif dan interaktif; 5) memberikan pengalaman yang nyata yang dapat menumbuhkan kegiatan berusaha sendiri di kalangan siswa; 6) menyampaikan materi secara seragam (baku); 7) efisiensi dalam waktu dan tenaga; 8) meningkatkan kualitas hasil belajar siswa; 9) memungkinkan proses belajar dapat dilakukan di mana saja dan kapan saja; dan 10) bahan pengajaran lebih terstruktur, logis dan jelas, dan metode mengajar akan lebih bervariasi (Yamashita, 2011)(Wiroatmodjo \& Sasonohardjo, 2002)(Kemp \& Dayton, 1985)(Arsyad, 2003)(Nana Sudjana, 2002).

Berdasarkan hasil diskusi dan survei di lapangan dengan pihak Musyawarah Guru Mata Pelajaran (MGMP) Sejarah, media pembelajaran Sejarah Indonesia belum banyak tersedia di pasaran, dalam artian belum ada pihak yang memproduksi media pembelajaran Sejarah Indonesia. Sampai saat ini telah banyak cara untuk membuat media pembelajaran sejarah, seperti diorama, poster, gambar, sampai pada replika-replika peninggalan sejarah. Tetapi replika benda-benda peninggalan sejarah tersebut terdapat di museum-museum, belum diproduksi secara massal. Keadaan tersebut kurang mendukung secara langsung proses belajar mengajar Sejarah. Selain itu, permasalahan utama yang dihadapi oleh guru di persekolahan berdasarkan hasil identifikasi dan analisis kebutuhan pelatihan adalah sebagai berikut: 1) Kurangnya keterampilan guru dalam menentukan dan memilih media pembelajaran Sejarah Indonesia; 2) Kurangnya keterampilan guru dalam membuat media pembelajaran Sejarah Indonesia, dan 3) Kurangnya keterampilan guru dalam memanfaatkan media dalam pembelajaran Sejarah Indonesia,

Merujuk permasalahan tersebut, laboratorium Pendidikan sejarah FPIPS Universitas Pendidikan Indonesia (UPI) sejauh ini telah melakukan beberapa riset pengembangan media pembelajaran sejarah dan sudah menghasilkan beberapa prototip benda sejarah pada masa pra sejarah, masa Islam dan masa Hindu-Budha di Indonesia (Darmawan, 2010). Penelitian tahun pertama dalam Skema Riset Andalan Perguruan Tinggi dan Industri (RAPID), tahun kedua Penelitian Unggulan Strategis Nasional, dan tahun ketiga Penelitian Pengembangan yang sudah dilakukan telah menghasilkan pengembangan model proses, prototip replika dan cetakan masa pra aksara (17 buah), masa Kerajaan Hindu Budha (14 buah), masa Kerajaan Islam (17 buah), peta e-pen (3 buah) masa pra aksara, masa Kerajaan Hindu Budha dan masa Kerajaan Islam (Saripudin, Darmawan, \& Tarunasena, 2018). Selain itu sudah dirumuskan pula business plan bersama perusahaan mitra. Untuk itu, diperlukan sosialisasi terhadap hasil riset sebelumnya untuk diaplikasikan ke masyarakat luas termasuk guru-guru Sejarah SMA di Kabupaten Sukabumi melalui pelatihan.

Berdasarkan hasil penjajagan kebutuhan pelatihan tersebut, maka dirumuskan masalah utama dari kegiatan ini adalah bagaimana membuat dan memanfaatkan media pembelajaran Sejarah Indonesia berupa replika dan peta e-pen? Masalah utama tersebut kemudian dirinci ke dalam beberapa pertanyaan, yaitu: (a) Bagaimana meningkatkan kemampuan guru dalam merancang media replica dan Peta e-pen? (b) Bagaimana tahap-tahap pelaksanaan pelatihan media pembelajaran Sejarah pada guru-guru SMA/MA? 
Didin Saripudin, Leli Yulifar, Diana Noor Anggraini Pelatihan Pembuatan dan Pemanfaatan Replika Sejarah dan Peta E-Pen Bagi Guru-Guru SMA/MA

\section{Metode Pelaksanaan}

Pendekatan pelatihan yang digunakan merujuk pada Malcom Knowles (dalam Lieb, 1991) dengan menerapkan pendekatan pembelajaran pengalaman (experiential learning). Pendekatan experiential learning sebagai suatu proses dimana pengalaman-pengalaman individu direfleksikan dan dari padanya timbul gagasan atau pengetahuan-pengetahuan baru. Pengalaman peneliti dalam melakukan penelitian media pembelajaran selama beberapa tahun menjadi poin pendukung dalam memberikan pembelajaran khusus kepada guru-guru. Proses pembelajaran bermula dari adanya suatu pengalaman yang diobservasi dan direfleksikan. Dari hasil proses tersebut, individu akan membentuk konsep-konsep abstrak yang kemudian dicobakan pada berbagai situasi baru. Mencoba menerapkan pada situasi baru suatu konsep abstrak yang telah dibentuk, memberikan suatu pengalaman baru lagi bagi individu, demikian seterusnya proses pembelajaran berlangsung, seperti sebuah siklus. Dengan menggunakan model Experiential Learning, maka peran terpenting seorang trainer dalam sebuah pelatihan adalah menjadi fasilitator (Achmat, 2005). Sebagai fasilitator ia harus menciptakan situasi belajar yang memungkinkan semua peserta memperoleh pengalaman baru atau membantu peserta menata pengalamannya di masa lampau dengan cara baru (Greenway, 2005).

Adapun metode pelatihan yang digunakan dengan melibatkan aktifitas-aktifitas yang bersifat participant-centered (berpusat pada peserta) dapat dilakukan melalui role-play, observasi, diskusi, dan brainstorming (Fowlie, 2000). Metode-metode tersebut memang hanya bisa dijalankan jika para pesertanya mau terlibat secara aktif. Oleh karenanya, dalam pelaksanaannya dirancang agar menyenangkan untuk dilakukan, mudah, tidak melelahkan, didasarkan pada pengalaman pribadi peserta, dan dilakukan dalam kelompok-kelompok kecil. Adapun prosedur pelaksanaan kegiatan In $\mathrm{On}$ Training Service ini dilaksanakan dengan menerapkan model In1 - On - In2 namun karena terjadi beberapa kendala maka dapat dilaksanakan In1 dan On dengan rincian kegiatan sebagai berikut.

Tahap In1, pada tahap ini empat orang narasumber akan menyampaikan struktur program kegiatan. Selanjutnya, mengidentifikasi kebutuhan peserta (analisis kebutuhan) dengan memfokuskan pelatihan pada beberapa struktur program yang dibutuhkan oleh peserta.

Tahap On, pada tahap ini, masing-masing peserta melakukan belajar secara mandiri dengan mengembangkan media pembelajaran Sejarah dan mengisi jurnal reflektif belajar mandiri, melaksanakan pembelajaran di sekolah masing-masing dengan mengimplementasikan pengetahuan yang didapatkannya pada tahap In1 dan mengisi jurnal reflektif pelaksanaan pembelajaran.

Gambaran dari model In-On dapat dilihat pada diagram di bawah ini:

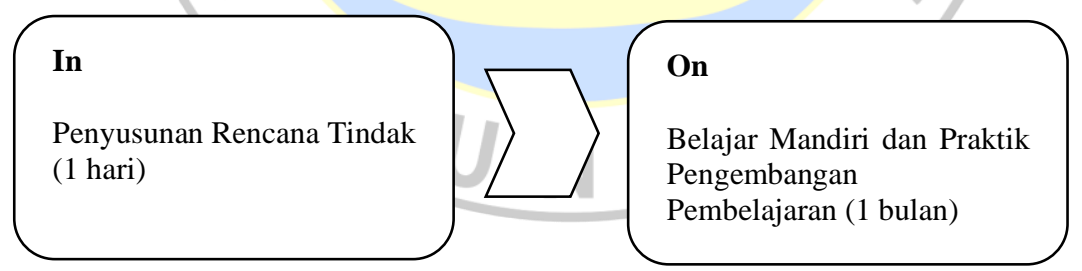

\section{Gambar 1. Model In1-On-In2}

Khalayak yang menjadi sasaran in/on training service pengembangan bahan ajar sejarah lokal bagi guru-guru SMA adalah para guru Sejarah pada Sekolah Menengah Atas (SMA) di Kabupaten Sukabumi dengan peserta berjumlah 60 orang. Pada umumnya berlatar belakang pendidikan sarjana (S1) bidang Pendidikan sejarah dan sebagian kecil ada yang sudah memiliki pendidikan magister (S2). Tak jarang latar belakang pendidikan peserta pelatihan tidak sesuai dengan bidang mata pelajaran yang diampu. Beberapa ada yang berlatar belakang sarjana Pendidikan geografi, sarjana sosial, dan sarjana Pendidikan ekonomi. Keberagaman latar belakang pendidikan tidak mengindahkan kemampuan pengalaman yang mereka miliki selama mengajar. 
Didin Saripudin, Leli Yulifar, Diana Noor Anggraini Pelatihan Pembuatan dan Pemanfaatan Replika Sejarah dan Peta E-Pen Bagi Guru-Guru SMA/MA

\section{Hasil dan Pembahasan}

\subsection{Aplikasi Ilmu dalam Pelatihan Media Pembelajaran Sejarah}

Pengabdian berbasis bidang ilmu difokuskan pada keimuan peneliti dalam pembelajaran Sejarah. Pembelajaran Sejarah yang dikembangkan meliputi berbagai komponen pembelajaran yang di antaranya materi, metode, media, sumber belajar, dan evaluasi. Pengabdian ini dilakukan pengembangan terhadap media pembelajaran Sejarah. Media yang dikembangkan berupa replika benda-benda peninggalan sejarah dan peta e-pen. Pengembangan produksi media pembelajaran Sejarah Indonesia yang dihasilkan berupa: 1) replika benda-benda sejarah, manusia purba, 2) replika bendabenda sejarah pada masa Hindu Budha, 3) replika benda-benda sejarah pada masa Islam. Setiap masa/babak dijadikan satu set/kit. Jadi kita memproduksi sebanyak 3 set/kit.

Kit 1 terdiri atas 17 Replika benda sejarah dan manusia purba yang terdiri dari: Megantropus Erectus, Pithecantropus Erectus, Homo Soloensis, Tengkorak Homo Erectus, Tengkorak Homo Sapiens, Kapak Genggam, Kapak Lonjong, Kapak Persegi, sarkofagus, kapak corong, flakes, arca pra sejarah, menhir, nekara, ani-ani, dan perahu bercadik.

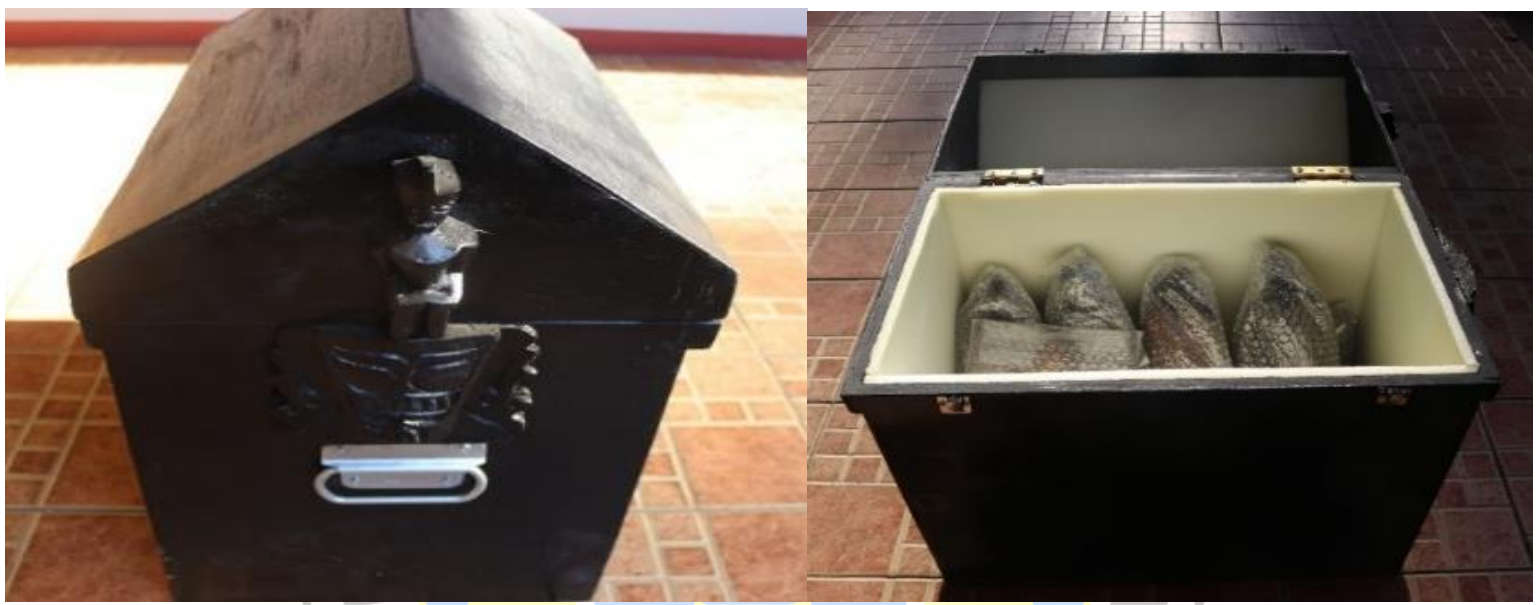

Gambar 1. Replika Benda Sejarah Pada Masa Pra Aksara

Kit 2 terdiri atas 14 Replika benda sejarah pada masa Hindu Buddha yang terdiri dari: Prasasti Ciaruteun, Prasasti Yupa, Arca Brahma, Arca Brahma, Arca Wisnu, Arca Syiwa, Candi Borobudur, Candi Prambanan, Candi Jawi, Stupa, Relief Borobudur, Mata Uang Majapahit, Lambang Negara Majapahit, Seni Kriya Majapahit, dan Keropak.

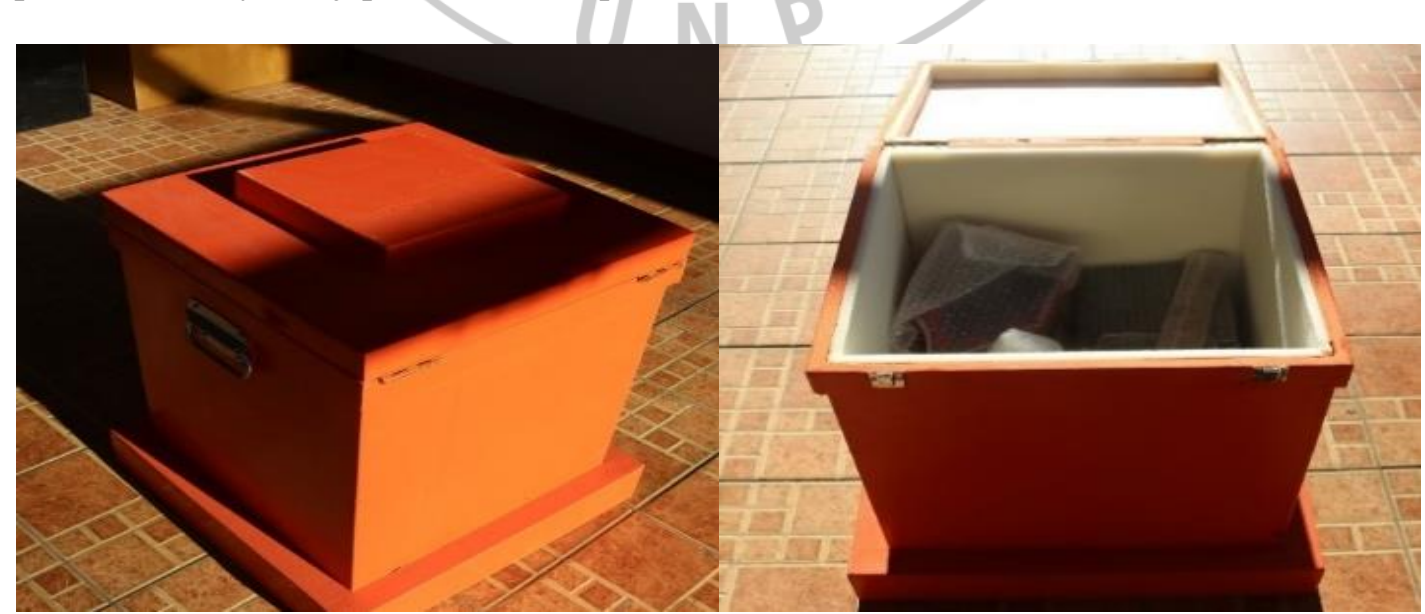

Gambar 2. Replika Benda Sejarah Pada Masa Hindu Buddha 
Kit 3 terdiri atas 17 Replika benda sejarah pada masa Islam yang terdiri dari: Makam Sultan Malikus Saleh (Aceh), Makam Maulana Malik, Stempel, Masjid Khas Jawa, Wayang Sadat, Wayang Golek, Mahkota Aceh, Mahkota Melayu, Mahkota Mataram, Bendera Kesultanan, Bendera Kesultanan Surakarta, Bendera Kesultanan Banten, Bendera Kesultanan Demak, Bendera Kesultanan Ternate, Bendera Kesultanan Gowa, Bendera Kesultanan Jogja, dan Bendera Kesultanan Tidore.

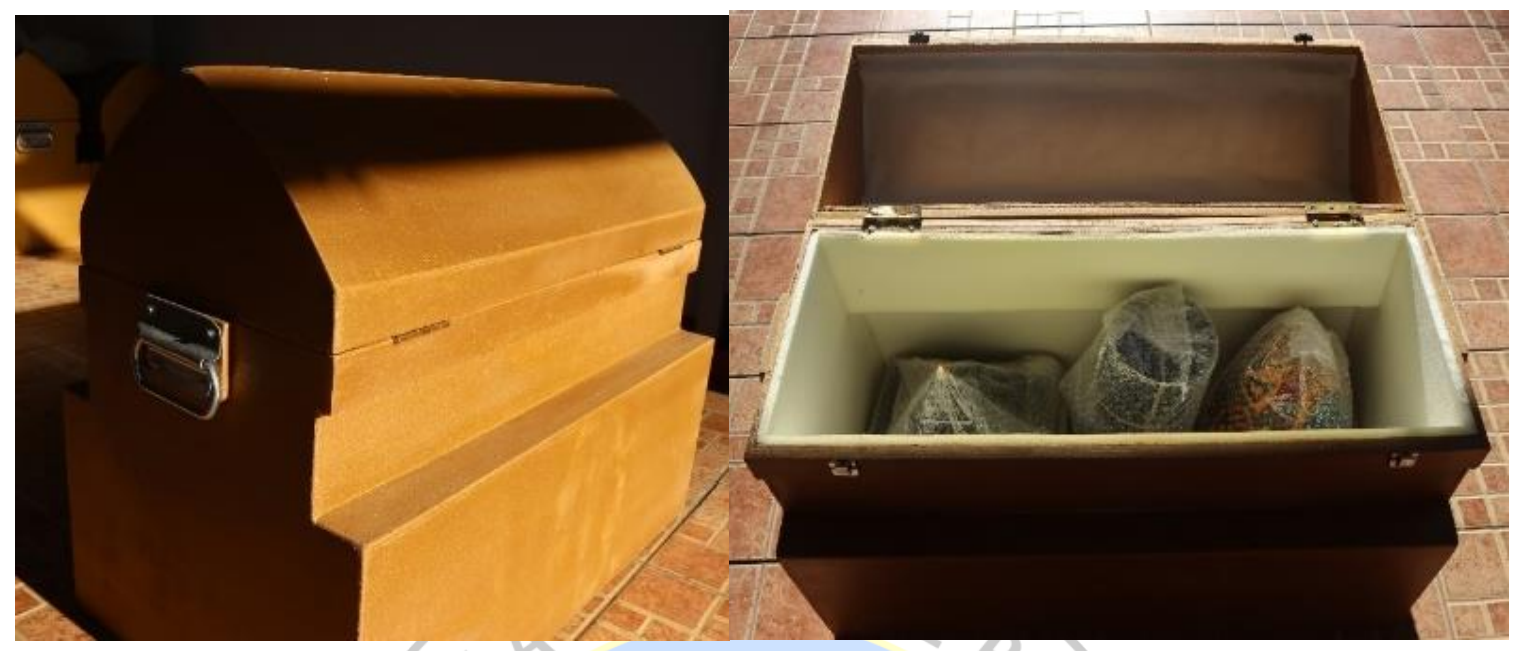

Gambar 3. Replika Benda Sejarah Pada Masa Kerajaan Islam

Adapun langkah-langkah Pembuatan dan Produksi Replika adalah sbb: Bahan: clay, resin, fiber matt, rubber silicone, gypsum casting Teknik: (a) Pembuatan master/prototype dengan menggunakan bahan clay/tanah liat. Kemudian setelah master/prototype sudah selesai lalu mulai ketahap pembuatan cetakan dengan menggunakan rubber silicone dengan teknik cor. Proses pembuatan cetakan dibagi menjadi dua bagian yaitu bagian kepala dan bagian rahang bawah. Proses ini membutuhkan waktu kurang lebih 30-60 menit agar cetakan terbentuk dengan sempurna dan tahan lama. (b) Setelah rubber silicon sudah kering kemudian bagian luar cetakan dilapisi dengan resin dan fiber matt, Lapisan ini bertujuan agar bentuk cetakan tidak berubah sesuai dengan master/prototype yang dicetaknya, proses ini membutuhkan waktu kurang lebih 90-120 menit. (c) Setelah cetakan sudah selesai, lalu ambil prototype yang ada didalam silicon tadi. kemudian aduk cairan resin dan catalyst (pengeras) dengan perbandingan 1: 10 artinya banyak katalis adalah 1/10. (d) Kemudian tuangkan kedalam cetakan yang sudah jadi tadi, lalu tunggu sampai mengeras. (e) Selanjutnya adalah proses finishing yaitu mewarnai hasil cetakan dengan menggunakan cat duco dengan teknik brush. (f) Untuk produksi, bahan-bahan dicetak menggunakan cetakan yang dihasilkan sebelumnya kemudian diperbanyak dengan jumlah yang ditentukan berdasarkan bahan yang diatur komposisinya.

Sedangkan untuk pengembangan prototipe e-pen menggunakan teknologi yang sudah dikembangkan oleh "Pudak Scientific" yang kemudian disempurnakan dan diisi konten berkenaan dengan Sejarah Indonesia. Peta e-pen dibagi menjadi tiga yang di antaranya : 1) Peta persebaran situs peninggalan masa pra aksara; 2) Peta Kerajaan Hindu Budha, dan 3) Peta Masa Kerajaan Islam. Adapun prosedur pengembangan Media Peta E-Pen Konten Sejarah di antaranya sebagai berikut: (a) Menentukan tiga peta untuk e-pen (Peta Persebaran situs peninggalan masa praaksara, Peta Kerajaan Hindu-Budha, dan Peta Masa Kerajaan Islam). (b) Menentukan bahan peta e-pen untuk media pembelajaran. (c) Menentukan dimensi (ukuran) media peta e-pen, (d) Mengeksplor dan mengidentifikasi konten ketiga tema peta berdasarkan sumber-sumber yang tersedia, (e) Mengembangkan deskripsi dari konten lokasi situs bersejarah yang telah ditentukan, (f) Menentukan teknis pengisian suara deskripsi konten peta sejarah, beserta personal pengisi suara, (g) Validasi dan akurasi konten deskripsi sejarah untuk direkam ke dalam memory e-pen, (h) Melakukan proses perekaman deskripsi per lokasi bersejarah setiap peta, (i) Validasi hasil dan kualitas rekaman deskripsi, dan (j) Bentuk final peta e-pen sejarah. 
Setelah terbentuknya media peta e-pen konten sejarah secara final, maka dapat digambarkan Peta Peta Persebaran situs peninggalan masa praaksara, Masa Hindu Budha, dan Masa Islam sebagai berikut.
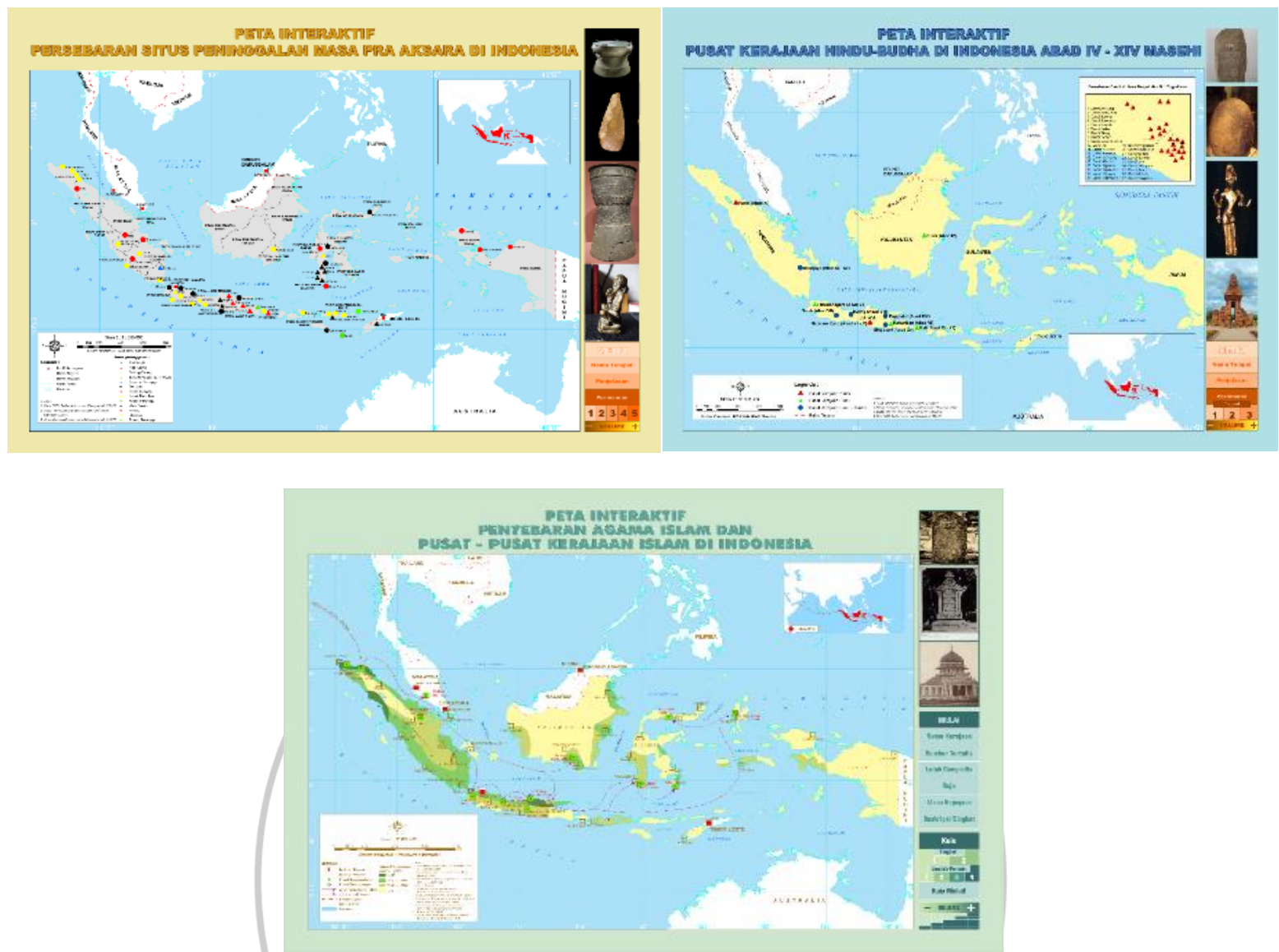

Gambar 4. Peta E-Pen Persebaran Situs Peninggalan Masa Pra Aksara, Hindu Budha dan Islam

Media pembelajaran Sejarah Indonesia berupa replika dan peta e-pen ini belum tersedia di pasaran sedangkan media ini sangat diperlukan untuk membantu pembelajaran Sejarah Indonesia terutama pada tingkat SMA/MA dan SMK. Perlu diperhatikan bahwa upaya pelatihan media efektif dapat meningkatkan kualitas profesional para guru khususnya di dalam kompetensi pengembangan media pembelajaran merupakan kegiatan yang dibutuhkan dalam suatu proses pembelajaran. Salah satu cara yang dapat dilakukan untuk meningkatkan kualitas profesional para guru tersebut diantaranya melalui penyelenggaraan pelatihan pengembangan media pembelajaran Sejarah pada para guru. Sebagai langkah awal, kegiatan ini akan dimulai pada guru SMA di Kabupaten Sukabumi.

\subsection{Pelaksanaan Kegiatan Pelatihan}

Penyelenggaraan pelatihan media pembelajaran Sejarah dibagi menjadi empat tahap dilakukan oleh Tim Pengabdian dan Panitia Penyelenggara, yaitu Tahap Persiapan, Tahap Pelaksanaan Pelatihan, Tahap Evaluasi, dan Tahap Rencana Tindak Lanjut yang dilakukan secara daring.

\subsubsection{Tahap Persiapan dalam pelaksanaan}

Persiapan operasional ini antara lain meliputi: (a) Pemberitahuan menggunakan Flyer dan Whatsapp grup kepada peserta; (b) Pemberitahuan/Undangan melalui Whatsapp dan Email kepada Fasilitator/Nara Sumber; (c) Menyediakan akun zoom meeting dan link pendaftaran pelatihan; (d) Mempersiapkan Kelengkapan Bahan Pelatihan, (e) Mempersiapkan Penggantian Kuota Kepada Peserta. 
Didin Saripudin, Leli Yulifar, Diana Noor Anggraini Pelatihan Pembuatan dan Pemanfaatan Replika Sejarah dan Peta E-Pen Bagi Guru-Guru SMA/MA

\subsubsection{Tahap Pelaksanaan Pelatihan}

Kegiatan pengabdian dilaksanakan secara daring melalui zoom meeting yang bekerjasama dengan MGMP Sejarah Kabupaten Sukabumi. Pelaksanaan pelatihan secara umum mengikuti alur pokok kegiatan pelaksanaan pelatihan sebagai berikut: (a) Registrasi peserta pelatihan melalui google form; Peserta pelatihan melakukan registrasi dimana berdasarkan Daftar Hadir tercatat peserta pelatihan sebanyak 60 orang. (b) Pembukaan Pelatihan; Kegiatan pelatihan dimulai dengan pembukaan dan sambutan-sambutan oleh ketua MGMP Kabupaten Sukabumi dan Ketua Pengabdian dari UPI. Acara dipandu oleh seorang moderator. (c) Pencairan Suasana; Pencairan suasana diisi dengan perkenalan, motivasi, dan pengkondisian pelatihan supaya lebih lebih fokus dan kondusif untuk pencapaian tujuan.

Instruktur dan materi dalam pelatihan Tahap In 1 adalah : (a) Pemateri 1 (Multimedia dalam Pembelajaran Sejarah Secara Daring); (b) Pemateri 2 (Kreativitas Guru dalam Pemanfaatan Media Pembelajaran Sejarah); (c) Pemateri 3 (Pengembangan dan Penggunaan Media Replika Benda-Benda Sejarah).

Tahap On peserta melakukan kegiatan tugas mandiri perencanaan dan pelaksanaan "Pengembangan media pembelajaran sejarah yang disesuaikan dengan KI/KD masing-masing". Monitoring dilakukan oleh Tim PkM bersama MGMP terhadap proses pengerjaan tugas mandiri yang telah dikerjakan oleh peserta. Pada kegiatan pelatihan guru-guru dikelompokkan menjadi 3 pembabakan dalam membuat media pembelajaran, yakni masa pra aksara, masa Hindu Budha dan masa Islam. Kegiatan selanjutnya mengembangkan media pembelajaran sejarah di sekolah masing-masing dengan mengimplementasikan pengetahuan dan keterampilan yang didapatkannya pada tahap In1. Pada tahap ini dilakukan monitoring oleh tim PkM Bidang Ilmu, MGMP Sejarah dan Dinas Pendidikan Kabupaten Sukabumi.

Kegiatan pelatihan ini dilakukan dengan melibatkan berbagai institusi terkait dengan melaksanakan pelatihan pengembangan media pembelajaran Sejarah. Adapun institusi yang dilibatkan dalam kegiatan ini beserta peran dan manfaat yang diperolehnya adalah:

a) MGMP Sejarah Kabupaten Sukabumi

Peran MGMP (Musyawarah Guru Mata Pelajaran) Sejarah Kabupaten Sukabumi adalah sebagai mitra yang berpengaruh dalam mengkoordinasikan peserta pelatihan yang secara langsung merupakan anggota dari MGMP Sejarah Kabupaten Sukabumi. Manfaat kegiatan bagi MGMP ini adalah sebagai bagian terintegrasi dari kegiatan: (a) pelatihan profesional yang diadakan secara terprogram dalam kinerja MGMP Sejarah Kabupaten Sukabumi; (b) melaksanakan koordinasi dan kerja sama dalam hal pengintegrasian dasar pemahaman dan implementasi penerapan media dalam pembelajaran Sejarah Indonesia ; (c) menyusun rencana dan inovasi pembelajaran Sejarah yang tepat dan efektif; (d) membahas model pembelajaran yang tepat dalam penyelenggaraan pembelajaran Sejarah secara daring.

b) Lembaga Penelitian dan Pengabdian Masyarakat UPI

Lembaga Penelitian dan Pengabdian Masyarakat (LPPM) memiliki peran sebagai alat perangkat pendukung dalam memberikan persetujuan dan ijin dalam pelaksanaan kegiatan pelatihan ini.

c) Ikatan Alumni Departemen Pendidikan Sejarah UPI

Peran IKA Departemen Pendidikan Sejarah sebagai penyedia instruktur pelatihan dengan mempertimbangkan keahlian sebagai berikut: 1) Tim peneliti model pembelajaran Sejarah; 2) dosen rumpun pembelajaran Sejarah, dan 3) menghimpun peserta yang berasal dari alumni Sejarah yang pada saat ini sudah berprofesi menjadi guru.

d) Mahasiswa Departemen Pendidikan Sejarah UPI

Mahasiswa yang dilibatkan dalam kegiatan pelatihan ini berjumlah 2 orang, dengan tujuan untuk membantu secara teknis (persiapan, moderator, notulasi dan dokumentasi), serta mengamati secara empiris pelaksanaan kegiatan yang terkait dengan pengabdian. 
Didin Saripudin, Leli Yulifar, Diana Noor Anggraini Pelatihan Pembuatan dan Pemanfaatan Replika Sejarah dan Peta E-Pen Bagi Guru-Guru SMA/MA

\subsubsection{Tahap Evaluasi Kegiatan}

Langkah kegiatan selanjutnya diadakan evaluasi pelatihan yang dilaksanakan dengan tujuan: (a) Menemukan bagian-bagian mana saja dari suatu pelatihan pengembangan media Sejarah pada Mata Pelajaran Sejarah Indonesia yang berhasil mencapai tujuan, serta bagian-bagian yang tidak mencapai tujuan atau kurang berhasil sehingga dapat dibuat langkah-langkah perbaikan yang diperlukan. (b) Memberi kesempatan kepada peserta untuk menyumbangkan pemikiran dan saran saran serta penilaian terhadap efektifitas program pelatihan pengembangan media pada Mata Pelajaran Sejarah yang dilaksanakan. (c) Mengetahui sejauh mana dampak kegiatan pelatihan pengembangan media Sejarah pada Mata Pelajaran Sejarah terutama yang berkaitan dengan terjadinya perilaku di kemudian hari. (d) Identifikasi kebutuhan pelatihan untuk merancang dan merencanakan kegiatan pelatihan selanjutnya.

Atas dasar pertimbangan-pertimbangan tersebut, maka kegiatan evaluasi pelatihan ini berupa: (a) Evaluasi Proses Pelatihan. Evaluasi proses adalah evaluasi yang dilakukan terhadap langkah-langkah kegiatan selama proses pelatihan berlangsung. Evaluasi proses dilakukan dengan mengungkapkan pendapat seluruh peserta tentang materi/isi pelatihan dan proses pelatihan. Evaluasi proses pelatihan dilakukan dengan model refleksi bersama antara tim pengabdian, Ketua/Sekretaris MGMP Sejarah dan peserta kegiatan. (b) Evaluasi Hasil Pelatihan. Evaluasi hasil pelatihan berguna untuk mengetahui dan mengukur akibat-akibat yang ditimbulkan oleh suatu tindakan pelatihan. (c) Monitoring Evaluasi. Monitoring dan evaluasi kegiatan ini dilakukan oleh tim PkM Bidang Ilmu, MGMP Sejarah dan Dinas Pendidikan Kabupaten Sukabumi daam rangka mengumpulkan informasi, memberikan pertimbangan dan memutuskan solusi perbaikan untuk kegiatan selanjutnya.

\subsubsection{Tahap Rencana Tindak Lanjut}

Hasil evaluasi menjadi masukan dalam melakukan rencana tindak lanjut kegiatan pelatihan, diantaranya teridentifikasi beberapa keinginan untuk melakukan program lanjutan, yaitu: 1) pendampingan implementasi pengembangan media pada Mata Pelajaran Sejarah Indonesia: 2) Pendampingan penyusunan media pembelajaran Sejarah secara daring; 3) Pendampingan penyusunan multimedia sesuai tuntutan kurikulum 2013; dan 4) Pendampingan untuk analisis tindakan kelas dalam menerapkan media pembelajaran Sejarah dalam Kurikulum 2013 pada Mata Pelajaran Sejarah Indonesia. Kegiatan tindak lanjut ini tentunya membutuhkan dukungan biaya, sarana dan prasarana pendukung, kerjasama dengan MGMP, dan tentunya dukungan terpenting dari perguruan tinggi (UPI), khususnya LPPM melalui program hibah pengabdian kepada masyarakat yang memadai sehingga diharapkan pelaksanaan kegiatan dapat mencapai hasil yang optimal.

\subsection{Analisis Pembahasan}

Hasil pelatihan menunjukkan bahwa pengembangan media pembelajaran sejarah berupa replika dan peta e-pen yang dilakukan oleh guru-guru Sejarah SMA/MA merupakan sarana efektif dalam membantu guru untuk membentuk kreativitasnya membuat media replica dan peta e-pen. Hal ini dapat dianalisis melalui klarifikasi sebagai berikut:

Pertama, guru yang professional adalah guru yang mampu memiliki keahlian, kemahiran, dan kecakapan yang memenuhi syarat mutu. Keahlian dalam membuat media pembelajaran pun merupakan bagian kepemilikan persyarat tersebut digunakan untuk melaksanakan pembelajaran yang baik (Susetyo \& Noermanzah, 2020)(Noermanzah, 2015). Media pembelajaran Sejarah menjadi alat bantu guru dalam mengajar dan sarana pembawa pesan dari sumber belajar ke penerima pesan belajar (siswa) untuk tujuan pendidikan sejarah. Oleh karena itu kualitas seperti berpikir kronologis, pemahaman sejarah, kemampuan analisis dan penafsiran sejarah, kemampuan penelitian sejarah, kemampuan analisis isu dan pengambilan keputusan (historical issues-analysis and decision making) menjadi tujuan penting dalam pendidikan sejarah (Hasan, 1997). Melalui media pembelajaran Sejarah tersebut, maka tujuan penting dari pendidikan sejarah dapat tersalurkan, karena media dapat dijadikan sebagai penyaji dan penyalur pesan, media belajar dalam hal hal tertentu, dan dapat mewakili guru menyajikan informasi belajar kepada siswa (Komalasari \& Saripudin, 2017).

Kedua, pelatihan media pembelajaran sejarah berupa replica dan peta e-pen menjadi sarana yang efektif dalam meningkatkan kompetensi guru melalui perkembangan teknologi pendidikan yang 
dibutuhkan saat ini. Apabila ditelaah lebih lanjut, berkembangnya paradigma dalam teknologi pendidikan mempengaruhi perkembangan media pembelajaran (Yamashita, 2011), di antaranya : 1) dalam paradigma pertama, media pembelajaran sama dengan alat peraga audio visual yang dipakai oleh instruktur untuk melaksanakan tugasnya; 2) dalam paradigma kedua, media dipandang sebagai sesuatu yang dikembangkan secara sistemik dan berpegang kepada kaidah komunikasi; 3) dalam paradigma ketiga, media dipandang sebagai bagian integral dalam sistem pembelajaran dan karena itu menghendaki adanya perubahan pada komponen-komponen lain dalam proses pembelajaran; 4) dalam paradigma keempat, lebih dipandang sebagai salah satu sumber yang dengan sengaja dan bertujuan dikembangkan dan atau dimanfaatkan untuk keperluan belajar.

Ketiga, integrasi media replika dan peta e-pen dalam pembelajaran sejarah dapat memotivasi hasil belajar siswa ke arah yang lebih baik. Media pengajaran dapat meningkatkan proses belajar siswa yang pada gilirannya diharapkan dapat mempertinggi hasil belajar yang dicapainya. Alasan media pengajaran dapat mempertinggi proses belajar siswa adalah: (1) pengajaran akan lebih menarik perhatian siswa sehingga menumbuhkan motivasi belajar; (2) bahan pengajaran akan lebih jelas maknanya sehingga akan lebih dapat dipahami oleh para siswa, dan memungkinkan siswa menguasai tujuan pengajaran secara lebih baik; (3) metode mengajar akan lebih bervariasi, tidak semata-mata komunikasi verbal melalui penuturan kata-kata oleh guru atau dosen sehingga siswa tidak mengalami kebosanan; (3) siswa lebih banyak melakukan kegiatan belajar, tidak hanya mendengarkan penjelasan dari guru tetapi juga aktivitas lain seperti mengamati, mendengar, melakukan/mendemonstrasikan, dan lain-lain (N Sudjana \& Rivai, 1998).

Keempat, pengembangan media replika benda sejarah dan peta e-pen merupakan media efektif dalam membantu peserta didik memiliki pengalaman praktik langsung merupakan media yang paling efektif untuk pencapaian hasil pembelajaran, karena memberikan pengalaman konkrit pada peserta didik. Hal ini sejalan dengan paradigma pembelajaran Sejarah dirancang untuk membekali peserta didik dengan keterampilan dan cara berfikir sejarah, membentuk kesadaran menumbuh kembangkan nilainilai kebangsaan, mengembangkan inspirasi, dan mengaitkan peristiwa lokal dengan peristiwa nasional dalam satu rangkaian Sejarah Indonesia. Mata Pelajaran Sejarah Indonesia adalah kajian tentang berbagai peristiwa sejarah di Indonesia ditujukan untuk mengenal jati diri bangsanya dan menjadikannya sebagai landasan dalam membangun kehidupan berbangsa dan bernegara pada masa kini dan masa yang akan datang.

\section{Kesimpulan}

Pengabdian berbasis bidang ilmu difokuskan pada keimuan peneliti dalam pembelajaran Sejarah. Pengabdian ini dilakukan pengembangan terhadap media pembelajaran Sejarah berupa replika bendabenda peninggalan sejarah dan peta e-pen. Pelatihan media pembelajaran Sejarah Indonesia yang dihasilkan berupa: 1) replika benda-benda sejarah, manusia purba, 2) replika benda-benda sejarah pada masa Hindu Budha, 3) replika benda-benda sejarah pada masa Islam. Selanjutnya peta e-pen dibagi menjadi tiga yang di antaranya: 1) Peta persebaran situs peninggalan masa pra aksara; 2) Peta Kerajaan Hindu Budha, dan 3) Peta Masa Kerajaan Islam. Setiap masa/babak dijadikan satu set/kit, sehingga pada kegiatan pelatihan guru-guru dikelompokkan menjadi 3 pembabakan dalam membuat media pembelajaran. Penyelenggaraan pelatihan media pembelajaran Sejarah dibagi menjadi empat tahap dilakukan oleh Tim Pengabdian dan Panitia Penyelenggara, yaitu Tahap Persiapan, Tahap Pelaksanaan Pelatihan, Tahap Evaluasi, dan Tahap Rencana Tindak Lanjut yang dilakukan secara daring. Pelatihan ini melibatkan MGMP Sejarah Kabupaten Sukabumi, LPPM UPI, IKA Departemen Pendidikan Sejarah, dan mahasiswa Departemen Pendidikan Sejarah.

\section{Daftar Pustaka}

Achmat, Z. (2005). Efektifitas Pelatihan Pengembangan Kepribadian dan Kepemimpinan dalam Meningkatkan Kepercayaan Diri Mahasiswa Baru UMM Tahun 2005/2006. Malang.

Arsyad, A. (2003). Media Pembelajaran. Jakarta: PT Raja Grafindo Persada. 
Didin Saripudin, Leli Yulifar, Diana Noor Anggraini Pelatihan Pembuatan dan Pemanfaatan Replika Sejarah dan Peta E-Pen Bagi Guru-Guru SMA/MA

Darmawan, W. (2010). Pengembangan Laboratorium Pendidikan Sejarah dalam Pembuatan Replika Benda-benda Peningalan Sejarah. Bandung: Jurusan Pendidikan Sejarah FPIPS UPI.

Fowlie, J. (2000). Emotional Intelligence: The Role of Self-Confidence in Preparing Business School Undergraduates for Placement/Employment. Retrieved from http://www.herts.ac.uk

Greenway, R. (2005). Experiential Learning Cycles. Retrieved from http://reviewing.co.uk/research/ learning.cycles.htm

Hasan, H. (1997). Kurikulum dan Buku Teks Sejarah. Kongres Nasional Sejarah 1996 Jakarta Sub Tema Perkembangan Teori Dan Metodologi Dan Orientasi Pendidikan Sejarah. Jakarta: Direktorat Jenderal Kebudayaan Departemen Pendidikan dan Kebudayaan.

Kemp, J. E., \& Dayton, D. . (1985). Planning and Producing Instructional Media. Cambridge: Harper an Rows Publisher.

Komalasari, K., \& Saripudin, D. (2017). Value-Based Interactive Multimedia Development through Integrated Practice for The Formation of Students' Character. Turkish Online Journal of Educational Technology, 16(4), 179-186.

Noermanzah, N. (2015). Peran Dosen Bahasa dan Sastra Indonesia dalam Mempertahankan Bahasa Indonesia sebagai Alat Pemersatu Negara Kesatuan Republik Indonesia pada Era Globalisasi. Prosiding Seminar Nasional Bulan Bahasa 2015. Retrieved from http://repository.unib.ac.id/11133/
din, D. (2009). Pengaruh Penerapan Multimedia dalam Pembelajaran Sejarah Terhadap kemampuan Berpikir Sejarah. Bandung.

Saripudin, D., Darmawan, W., \& Tarunasena, T. (2018). Developing Learning Media of Indonesian History to Raise Students' Historical Consciousness. New Educational Review, 53(1), 163-175.

Sudjana, N, \& Rivai, A. (1998). Media Pengajaran. Bandung: CV. Sinar.

Sudjana, Nana. (2002). Penilaian dan Hasil Proses Belajar Mengajar. Bandung: Remaja Rosdakarya.

Susetyo, B., \& Noermanzah, N. (2020). Peningkatan Profesionalisme Guru Bahasa Indonesia di Kabupaten Musirawas Sumatera Selatan Melalui Pelatihan Menulis Artikel Jurnal Ilmiah. ABDI: Jurnal Pengabdian Dan Pemberdayaan Masyarakat, 2(1), 28-34.

Tarunasena, T. (2012). Blended Learning Model Implemetation to Improve Critical Thinking Skill in History Learning. Historia: International Journal of History Education, 13(2), 1-10.

Wiroatmodjo, W., \& Sasonohardjo, S. (2002). Media Pembelajaran (Bahan Ajar Diklat Kewidyaiswaraan Berjenjang Tingkat Pertama). Jakarta.

Yamashita, Y. (2011). Media Pembelajaran. Retrieved February 25, 2012, from http://proskripsi.blogspot.com/2011/02/perancangan-media-pembelajaran.html. 